\title{
Association between Non-Alcoholic Steatohepatitis and Left Ventricular Diastolic Dysfunction in Type 2 Diabetes Mellitus (Diabetes Metab J 2020;44:267-76)
}

\author{
Sung Hoon Yu \\ Department of Endocrinology and Metabolism, Hanyang University Guri Hospital, Hanyang University College of Medicine, Guri, Korea
}

Non-alcoholic fatty liver disease (NAFLD) is the most prevalent liver disease, with an estimated prevalence of $20 \%$ to $30 \%$ [1]. NAFLD in type 2 diabetes mellitus (T2DM) is a common condition that can act synergistically to produce adverse outcomes [2]. NAFLD has subtypes from simple steatosis characterized by little to no inflammation to non-alcoholic steatohepatitis (NASH), characterized by hepatic steatosis accompanied by inflammatory activity, fibrosis progression, and cirrhosis [3,4].

Heart failure (HF) represents a major health burden, with a prevalence of more than 23 million patients and an annual medical cost of approximately 108 billion dollars worldwide [5]. Clinical interest in HF has traditionally focused on left ventricular (LV) systolic dysfunction [5].

In this article entitled, "Association between non-alcoholic steatohepatitis and left ventricular diastolic dysfunction in type 2 diabetes mellitus," Lee et al. [6] investigated the association between liver fibrosis and LV diastolic dysfunction in T2DM. They showed that LV diastolic dysfunction was significantly more prevalent in the NAFLD compared to the non-NAFLD group, and liver fibrosis was associated with LV diastolic dysfunction in patients with T2DM. These findings are consistent with previous reports that have shown an association between diastolic dysfunction and NAFLD characterized by impaired ventricular relaxation, increased myocardial thickness, and epicardial fat content [7-9].

However, there are issues not covered in this study. First, liver fibrosis was associated with diastolic dysfunction only in pa- tients without insulin resistance. Insulin resistance is a key mechanism in NAFLD and T2DM. NAFLD is recognized as the hepatic component of metabolic syndrome, as these conditions share insulin resistance as a common pathophysiological mechanism. Therefore, NAFLD is strongly associated with T2DM and abdominal obesity $[2,10]$. Because NAFLD and diastolic dysfunction share multiple metabolic risk factors for cardiovascular diseases [11], several studies have suggested that NAFLD is associated with LV diastolic dysfunction $[7,12]$. However, why this result is meaningful only in patients without insulin resistance was not discussed in the present study. Second, there was no adjustment for duration of hypertension in this study. LV remodeling depends on age, type of hypertension, blood pressure values, and duration of hypertension [13]. Therefore, it is reasonable to apply duration of hypertension as an adjustment factor.

In my perspective, it would be interesting to evaluate if improvement in NASH fibrosis with weight loss or medical intervention may result in improved diastolic function in T2DM. Further studies are also needed to better understand the mechanisms by which diastolic dysfunction progresses with progression of NASH.

\section{CONFLICTS OF INTEREST}

No potential conflict of interest relevant to this article was reported.
Corresponding author: Yu Sung Hoon (iD https://orcid.org/0000-0003-4391-4526 Department of Endocrinology and Metabolism, Hanyang University Guri Hospital, Hanyang University College of Medicine, 153 Gyeongchun-ro, Guri 11923, Korea E-mail: physicianyu@daum.net
This is an Open Access article distributed under the terms of the Creative Commons Attribution Non-Commercial License (https://creativecommons.org/licenses/by-nc/4.0/) which permits unrestricted non-commercial use, distribution, and reproduction in any medium, provided the original work is properly cited. 


\section{REFERENCES}

1. Browning JD, Szczepaniak LS, Dobbins R, Nuremberg P, Horton JD, Cohen JC, Grundy SM, Hobbs HH. Prevalence of hepatic steatosis in an urban population in the United States: impact of ethnicity. Hepatology 2004;40:1387-95.

2. Hazlehurst JM, Woods C, Marjot T, Cobbold JF, Tomlinson JW. Non-alcoholic fatty liver disease and diabetes. Metabolism 2016;65:1096-108.

3. Kleiner DE, Brunt EM, Van Natta M, Behling C, Contos MJ, Cummings OW, Ferrell LD, Liu YC, Torbenson MS, UnalpArida A, Yeh M, McCullough AJ, Sanyal AJ; Nonalcoholic Steatohepatitis Clinical Research Network. Design and validation of a histological scoring system for nonalcoholic fatty liver disease. Hepatology 2005;41:1313-21.

4. Younossi ZM, Koenig AB, Abdelatif D, Fazel Y, Henry L, Wymer M. Global epidemiology of nonalcoholic fatty liver disease: meta-analytic assessment of prevalence, incidence, and outcomes. Hepatology 2016;64:73-84.

5. Mozaffarian D, Benjamin EJ, Go AS, Arnett DK, Blaha MJ, Cushman M, de Ferranti S, Despres JP, Fullerton HJ, Howard VJ, Huffman MD, Judd SE, Kissela BM, Lackland DT, Lichtman JH, Lisabeth LD, Liu S, Mackey RH, Matchar DB, McGuire DK, Mohler ER 3rd, Moy CS, Muntner P, Mussolino ME, Nasir K, Neumar RW, Nichol G, Palaniappan L, Pandey DK, Reeves MJ, Rodriguez CJ, Sorlie PD, Stein J, Towfighi A, Turan TN, Virani SS, Willey JZ, Woo D, Yeh RW, Turner MB; American Heart Association Statistics Committee and Stroke Statistics Subcommittee. Heart disease and stroke statistics: 2015 update: a report from the American Heart Association. Circulation 2015;131:e29-322.
6. Lee H, Kim G, Choi YJ, Huh BW, Lee BW, Kang ES, Cha BS, Lee EJ, Lee YH, Huh KB. Association between non-alcoholic steatohepatitis and left ventricular diastolic dysfunction in type 2 diabetes mellitus. Diabetes Metab J 2020;44:267-76.

7. VanWagner LB, Wilcox JE, Colangelo LA, Lloyd-Jones DM, Carr JJ, Lima JA, Lewis CE, Rinella ME, Shah SJ. Association of nonalcoholic fatty liver disease with subclinical myocardial remodeling and dysfunction: a population-based study. Hepatology 2015;62:773-83.

8. Perseghin G, Lattuada G, De Cobelli F, Esposito A, Belloni E, Ntali G, Ragogna F, Canu T, Scifo P, Del Maschio A, Luzi L. Increased mediastinal fat and impaired left ventricular energy metabolism in young men with newly found fatty liver. Hepatology 2008;47:51-8.

9. Petta S, Argano C, Colomba D, Camma C, Di Marco V, Cabibi D, Tuttolomondo A, Marchesini G, Pinto A, Licata G, Craxi A. Epicardial fat, cardiac geometry and cardiac function in patients with non-alcoholic fatty liver disease: association with the severity of liver disease. J Hepatol 2015;62:928-33.

10. Tilg H, Moschen AR, Roden M. NAFLD and diabetes mellitus. Nat Rev Gastroenterol Hepatol 2017;14:32-42.

11. Trovato GM. Clinical research and methodology. The paradigm of fatty liver and atherosclerosis behind the chicken or the egg dilemma. Atherosclerosis 2016;249:228-9.

12. Trovato FM, Martines GF, Catalano D, Musumeci G, Pirri C, Trovato GM. Echocardiography and NAFLD (non-alcoholic fatty liver disease). Int J Cardiol 2016;221:275-9.

13. Radulescu D, Stoicescu L, Buzdugan E, Donca V. Patterns of left ventricular remodeling among patients with essential and secondary hypertension. Rev Med Chil 2013;141:1520-7. 